Article

\title{
An Electrochemical Impedance Study of Alkaline Water Splitting Using Fe Doped NiO Nanosheets
}

\author{
Zhen Qiu $^{1}{ }^{1}$, Yue $\mathrm{Ma}^{2}{ }^{2}$, Gunnar A. Niklasson ${ }^{1}{ }^{(D)}$ and Tomas Edvinsson ${ }^{1, *(D)}$ \\ 1 Department of Materials Science and Engineering, Solid State Physics, Uppsala University, \\ SE-75103 Uppsala, Sweden; zhenq@kth.se (Z.Q.); Gunnar.Niklasson@angstrom.uu.se (G.A.N.) \\ 2 Center for Nano Energy Materials, State Key Laboratory of Solidification Processing, School of Materials \\ Science and Engineering, Northwestern Polytechnical University, Xi'an 710072, China; \\ mayue04@nwpu.edu.cn \\ * Correspondence: tomas.edvinsson@angstrom.uu.se
}

check for updates

Citation: Qiu, Z.; Ma, Y.; Niklasson, G.A.; Edvinsson, T. An

Electrochemical Impedance Study of Alkaline Water Splitting Using Fe Doped NiO Nanosheets. Physchem 2021, 1, 69-81. https://doi.org/ $10.3390 /$ physchem 1010005

Academic Editor: José Solla Gullón

Received: 7 May 2021

Accepted: 24 May 2021

Published: 31 May 2021

Publisher's Note: MDPI stays neutral with regard to jurisdictional claims in published maps and institutional affiliations.

Copyright: (c) 2021 by the authors. Licensee MDPI, Basel, Switzerland. This article is an open access article distributed under the terms and conditions of the Creative Commons Attribution (CC BY) license (https:/ / creativecommons.org/licenses/by/ $4.0 /)$.

\begin{abstract}
Mixed nickel-iron (Ni-Fe) compounds have recently emerged as promising non-precious electrocatalysts for alkaline water splitting. The understanding of the charge-transfer mechanism involved in the multi-step Faradic reaction, however, is still limited for the overall electrochemical process. In this paper, electrochemical impedance spectroscopy (EIS) measurements of Fe incorporated $\mathrm{Ni}$ oxide nanosheets were used to study the reaction kinetics for both hydrogen (HER) and oxygen (OER) evolution reactions in alkaline media. Our results showed that Fe incorporation improves the catalytic property of $\mathrm{NiO}$ nanosheets because of the lower reaction resistance and faster intermediate transformations. Detailed EIS modeling enables a separation of the surface coverage relaxation from the charge transfer resistance, with an inductive behavior observed in the low-frequency range for HER, holding important information on the dominating reaction mechanism. For OER, the good agreement between the EIS experimental results and a model with an inductance loop indicated that similar inductive behavior would be determining the EIS response at very low frequencies. The physical significance of the elementary steps gives insight into the governing reaction mechanisms involved in the electron and hole charge transfer, as well as the inherent properties of catalysts and their surface coverage relaxation.
\end{abstract}

Keywords: alkaline water splitting; Fe doped $\mathrm{NiO}$ nanosheets; electrochemical impedance spectroscopy; inductance

\section{Introduction}

Electrochemical water splitting is a promising approach to produce hydrogen $\left(\mathrm{H}_{2}\right)$ for clean energy applications powered by renewable but intermittent energy sources, e.g., solar, tidal, and wind [1-4]. The sluggish kinetics of the cathodic HER and the anodic OER, however, require large overpotentials $(\eta)$ above the theoretical thermodynamic value of $1.229 \mathrm{~V}$. This fundamentally restricts the overall reaction efficiency and is important for applications since a high rate of $\mathrm{H}_{2}$ production is needed to offset the high capital cost of an installed system. To improve the energy conversion efficiency at high reaction rates, an effective electrocatalyst is needed to minimize the energy barrier of this uphill reaction $[5,6]$. Ever since Corrigan et al., [7] reported that iron impurities in nickel oxide electrodes can significantly lower the OER overpotential, Fe doped Ni-based electrocatalysts have been revisited by numerous research groups to reveal the role of Fe on the enhanced kinetics. Miller et al., [8] reported that the OER Tafel slope was reduced from $95 \mathrm{mV} /$ decade (undoped $\mathrm{NiO}_{\mathrm{x}}$ ) to $40 \mathrm{mV} /$ decade for $\mathrm{NiO}$ with $\mathrm{Fe}$ incorporation, indicating a mechanistic change in the rate-limiting step from the primary discharge of $\mathrm{OH}$ ions to the recombination of oxygen radicals. Recently, Boettcher et al., [9] reported that Fe impurities increase the electrical conductivity of $\mathrm{Ni}(\mathrm{OH})_{2} / \mathrm{NiOOH}$ and exert a partial-charge-transfer activation effect on $\mathrm{Ni}$, leading to an enhanced OER activity. On the other hand, the HER as an 
indispensable part of an efficient overall reaction has also attracted considerable attention. There are some studies about Fe incorporation into Ni-based electrocatalysts for HER in alkaline electrolytes, which show improved cathodic activity as well [10,11]. Hence, it is clear that adding Fe impurities into Ni-based catalysts is positive for both OER and HER, although the anode and cathode possess different interface behaviors for water electrolysis. Up to now, a variety of NiFe-based electrocatalysis has been investigated [12-15]; however, there still exists a significant controversy over the catalytically active metal redox state and electron transfer pathways [16-20]. To explore the complete mechanism, different kinds of characterization, e.g., in-situ spectroscopy and density functional theory (DFT) calculations, have been carried out to identify the pathways for the catalytic reactions [21-23].

In this work, electrochemical impedance spectroscopy (EIS) is used to investigate the influence of $\mathrm{Fe}$ on the intrinsic charge-transfer kinetic of $\mathrm{NiO}$ nanosheets, leading to enhanced activities for overall water splitting in alkaline media. The ability of EIS to cover a wide range of frequencies at different direct current (DC) potentials allows us to investigate and understand the electrochemical behavior of multistep processes that influence the catalytic property $[24,25]$. By monitoring the catalytic current density at different potentials, we found that the presence of Fe could change the reaction route, requiring a lower driving force, and thus, improve the catalytic property for both OER and HER. The observed low-frequency pseudo-inductive loop under HER is quantified to show the coverage change of adsorbed surface species, which also implies which reaction step is rate-determining. The fitting results of OER behavior indicate the probability of an inductive loop in a very low frequency range. Based on an extension of the equivalent circuits (ECs) proposed by Harrington and Conway (HC) [26], we provide an investigation of this effect under operation and elucidate an approach that can rationalize the phenomena involved in the $\mathrm{Fe}-\mathrm{NiO}$ system, thereby providing the rate-limiting reaction mechanism and kinetic properties for overall alkaline water splitting.

\section{Experimental Section}

\subsection{Chemicals}

All chemicals were used as received without any further purification. Sodium hydroxide $(\mathrm{NaOH}, \geq 97 \%)$, Nickel (II) nitrate hexahydrate $\left(\mathrm{Ni}\left(\mathrm{NO}_{3}\right)_{2} \cdot 6 \mathrm{H}_{2} \mathrm{O}, \geq 97 \%\right)$, Iron (III) nitrate nonahydrate $\left(\mathrm{Fe}\left(\mathrm{NO}_{3}\right)_{3} \cdot 9 \mathrm{H}_{2} \mathrm{O},>99.95 \%\right)$ and Poly(vinyl alcohol) (PVA) (Mw $=89,000-98,000$, 99\%) were purchased from Sigma-Aldrich (St. Louis, MO, USA). Nickel foam (NF) (Porosity $\geq 95 \%$, Purity $>99.99 \%, 1.6 \mathrm{~mm}$ thick) was used as a three-dimensional (3D) substrate, purchased from MTI Corporation, Richmond, CA, USA.

\subsection{Catalyst Electrode Fabrication}

The catalytic electrodes in this work were synthesized by a chemical bath deposition (CBD) method described in the following. Nickel foam (NF) was soaked under $1 \mathrm{M} \mathrm{HCl}$ solution for $30 \mathrm{~min}$ to remove any surface layer of $\mathrm{NiO}_{\mathrm{X}}$, then cleaned by deionized (DI) water and pure ethanol (volume ratio $=1$ ) and dried in air at $80^{\circ} \mathrm{C}$. Subsequently, $0.5 \mathrm{~g}$ PVA was dissolved in $40 \mathrm{~mL}$ Milli-Q water at $90{ }^{\circ} \mathrm{C}$ under constant magnetic stirring. For $\mathrm{Fe}-\mathrm{NiO} / \mathrm{NF}, 0.12 \mathrm{M} \mathrm{Fe}\left(\mathrm{NO}_{3}\right)_{3} \cdot 9 \mathrm{H}_{2} \mathrm{O}$ and $1 \mathrm{M} \mathrm{Ni}\left(\mathrm{NO}_{3}\right)_{2} \cdot 6 \mathrm{H}_{2} \mathrm{O}$ were added into the solution to complete the precursor preparation. The pre-treated nickel foam was then immersed into the precursor solution and kept at $85^{\circ} \mathrm{C}$ for $8 \mathrm{~h}$. The resultant material was cleaned by DI water to remove residual reactants on the surface and annealed in an oven with a heating rate of $5{ }^{\circ} \mathrm{C} \mathrm{min}^{-1}$ from room temperature to $550{ }^{\circ} \mathrm{C}$ and was kept at $550{ }^{\circ} \mathrm{C}$ for $3 \mathrm{~h}$ under ambient air conditions. The $\mathrm{NiO} / \mathrm{NF}$ was prepared analogously without iron salt in the precursor solution and was immersed for $12 \mathrm{~h}$.

\subsection{Material Characterization}

Scanning electron microscopy (SEM) analyses were performed using a high-performance Schottky field-emission micro-analyzer (Zeiss 1550 with AZtec EDS). X-ray diffraction (XRD) patterns were collected with a Bruker D8 Advance Twin-Twin using $\mathrm{Cu} \mathrm{K} \alpha$ radiation 
$(\lambda=0.15418 \mathrm{~nm})$. The Raman spectra were collected with a Renishaw micro Raman system (Renishaw, Wotton-under-Edge Gloucestershire, UK. ) at room temperature using 1800 lines/mm grating. A frequency-doubled Nd:YAG laser operating at $532 \mathrm{~nm}$ was used as an excitation source where the incident laser intensity was lowered to $10 \mathrm{~mW}$ using neutral density filters. All Raman spectra were collected with a resolution of $\sim 1 \mathrm{~cm}^{-1}$.

\subsection{Electrochemical Measurements}

Electrochemical characterization was carried out on a $\mathrm{CH} 760 \mathrm{C}$ electrochemical workstation (CH Instruments, Inc. Austin, TX, USA) using a standard three-electrode quartz cell in $1 \mathrm{M} \mathrm{NaOH}$ at room temperature. The working, counter, and reference electrodes were the as-prepared catalysts, platinum wire, and $\mathrm{Ag} / \mathrm{AgCl}(3 \mathrm{M} \mathrm{KCl})$, respectively. The $1 \mathrm{M}$ $\mathrm{NaOH}$ electrolyte was prepared from pure $\mathrm{NaOH}$ pellets and Milli-Q water. All potentials used in this work were measured vs. $\mathrm{Ag} / \mathrm{AgCl}(3 \mathrm{M})$ and transformed to values relative to the reversible hydrogen electrode (RHE) using the Nernst equation.

$$
\mathrm{E}_{\mathrm{RHE}}=\mathrm{E}_{\mathrm{Ag} / \mathrm{AgCl}}+0.210 \mathrm{~V}+0.059 \mathrm{pH}(\mathrm{pH}=14 \pm 0.2)
$$

The polarization curves were obtained by linear sweep voltammetry (LSV) with a scan rate of $1 \mathrm{mV} \mathrm{s}^{-1}$. Electrochemical impedance spectroscopy (EIS) measurements were carried out at different applied potentials from -1.4 to $0.7 \mathrm{~V} \mathrm{vs.} \mathrm{Ag} / \mathrm{AgCl}(3 \mathrm{M} \mathrm{KCl})$ in the frequency range of 1 to $10^{5} \mathrm{~Hz}$ with $5 \mathrm{mV}$ ac amplitude. The Tafel slope was obtained from LSV plots using the following equation, $\eta=b \times \log J+a$ where $J$ is current density with $100 \%$ iR correction, $R$ is the internal resistance of the electrochemical cell obtained from EIS, $\eta$ is the overpotential, and $b$ is the Tafel slope.

\section{Result and Discussion}

The surface morphology of the electrodes consisting of Fe-NiO (Figure 1a,e) and $\mathrm{NiO}$ nanosheets (Figure S1), deposited onto Ni foam, was characterized by scanning electron microscopy (SEM) and energy-dispersive X-ray spectroscopy (EDS) elemental mappings (Figure $1 \mathrm{~b}-\mathrm{d}$ ). The latter technique reveals a uniform dispersion of $\mathrm{Ni}, \mathrm{Fe}$, and $\mathrm{O}$ throughout the nanostructure. As shown in Figure S2, the thickness of the nanosheets is approximately $850 \mathrm{~nm}$. Raman spectroscopy (Figure 1f) is a versatile tool and further confirms that Fe ions are chemically bonded into the $\mathrm{NiO}$ lattice, which also corresponds with previous reports for Ni-Fe oxide systems [27-29]. The Raman peaks below $600 \mathrm{~cm}^{-1}$ in NiO can be ascribed to one-phonon (1P) Ni-O modes (TO and LO), two-phonon modes between $600 \mathrm{~cm}^{-1}$ and $1200 \mathrm{~cm}^{-1}$ (2TO, TO + LO, and 2LO), and magnon modes above $1200 \mathrm{~cm}^{-1}$ [30]. Magnons are excitations of spin waves that can occur in magnetically ordered materials [31], where a two-magnon (2 M) mode commonly was seen at $\sim 1500 \mathrm{~cm}^{-1}$ for $\mathrm{NiO}$ [30,32]. The Raman band at $509 \mathrm{~cm}^{-1}$ and $1014 \mathrm{~cm}^{-1}$ in $\mathrm{NiO}$ could be ascribed to the LO mode and the frequency-doubled 2LO mode, respectively. The weak band at $\sim 1500 \mathrm{~cm}^{-1}$ in $\mathrm{NiO}$ was well consistent with the $2 \mathrm{M}$ mode [30,33]. The positive shift of the 1P LO Raman band with $\mathrm{Fe}$ incorporation $(\mathrm{Fe}-\mathrm{NiO})$ indicated that $\mathrm{Fe}$ was inserted into the lattice of $\mathrm{NiO}$. The $2 \mathrm{M}$ Raman mode disappeared and this implied a change in the magnetic ordering with Fe incorporation, which agreed with previously reported broadening and damping of the $2 \mathrm{M}$ mode upon increased metal ion doping into NiO [34]. Furthermore, the LO mode at $550 \mathrm{~cm}^{-1}$ for the Fe-doped $\mathrm{NiO}$ was not fully frequency doubled into the 2LO mode at $1070 \mathrm{~cm}^{-1}$, reflecting that only the low wavenumber part of the $1 \mathrm{P}$ mode was coupled into the $2 \mathrm{LO}$ mode of $\mathrm{NiO}$, thereby demonstrating a local disorder of the $1 \mathrm{P} \mathrm{LO}$ mode with Fe doping. As seen in Figure S3, the X-ray diffraction (XRD) patterns at $37.3^{\circ}, 43.3^{\circ}$, $63.0^{\circ}, 75.4^{\circ}$, and $79.4^{\circ}$ of the $\mathrm{Fe}-\mathrm{NiO}$ and $\mathrm{NiO}$ nanosheets can be assigned to (111), (200), (220), (311), and (222) planes of cubic NiO (ICDD: 00-004-0835). There are no additional reflections from Fe-containing phases appearing in as-synthesized Fe-NiO. Moreover, the slightly broader peaks for $\mathrm{Fe}-\mathrm{NiO}$ indicate that Fe substitution leads to the suppression of the grain growth and structural disorder of $\mathrm{NiO}$ lattice, which is in agreement with other reported works $[35,36]$. 

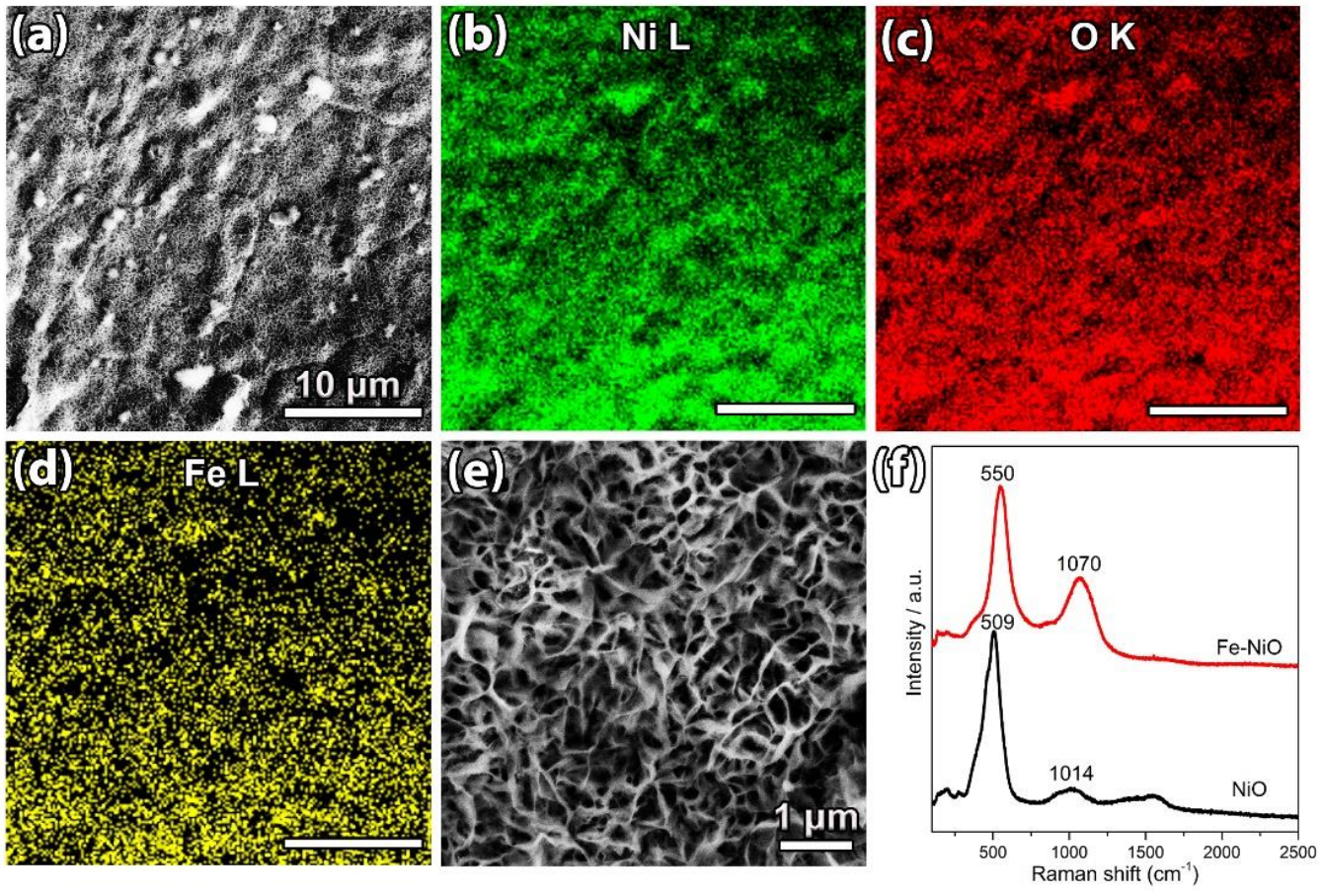

Figure 1. (a-d) Low-magnification SEM image and EDS elemental mapping of $\mathrm{Ni}, \mathrm{O}$, and Fe for $\mathrm{Fe}-\mathrm{NiO}$ nanosheets with the same scale bar. (e) High-magnification SEM image of Fe-NiO nanosheets. (f) Comparison of Raman spectra of $\mathrm{Fe}-\mathrm{NiO}$ and $\mathrm{NiO}$ nanosheets under $532 \mathrm{~nm}$ laser irradiation.

EIS analysis [16,37-39] has been widely used to reveal the electrochemical behaviors involved in reaction processes. As reported previously [40,41], the mechanism of HER in alkaline media follows two primary steps: (i) water molecules decompose to yield $\mathrm{OH}^{-}$ in the solution together with adsorbed atomic hydrogen $\left(\mathrm{H}_{\mathrm{ad}}\right)$ bound to metal $(\mathrm{M})$ atoms on the surface (Volmer reaction) followed by (ii) electrochemical desorption (Heyrovsky reaction) or $\mathrm{M}-\mathrm{H}_{\mathrm{ad}}$ recombination (Tafel reaction). The impedance of such a multistep process is complex and can be represented by different ECs, as shown by HC [26]. To model the HER process, we improved the inductive EC of HC by adding a series resistance $\left(\mathrm{R}_{1}\right)$, due to electrolyte and/or contacts and a high-frequency impedance due to the film or interfacial barriers (represented by $\mathrm{R}_{2}$ and $\mathrm{CPE}_{\mathrm{f}}$ with $\alpha=1$ ), as illustrated in Figure 2a. In addition, constant phase elements (CPE) were used to replace capacitances. In this so-called L-CPE model, the electrochemical charge-transfer interfacial reaction of the HER process was represented by a parallel connection of $C P E_{\mathrm{dl}}, \mathrm{R}_{3}$, and $\mathrm{L}-\mathrm{R}_{4}$ and occurred at moderate-to-low frequencies. Here $\mathrm{CPE}_{\mathrm{dl}}$ denotes the double layer constant phase element, $R_{3}$ is the reaction charge transfer resistance, while the $L-R_{4}$ series combination represents the additional part of the impedance response that is due to a changing surface coverage of adsorbed species. A CPE is an equivalent electrical circuit component that represents an imperfect capacitor and can be expressed as:

$$
\mathrm{Z}_{\mathrm{CPE}}^{*}=\left[\mathrm{Q}(\mathrm{j} \omega)^{\alpha}\right]^{-1}
$$

where $\omega$ is the angular frequency, $\mathrm{Q}$ is a parameter related to the capacitance, and $\alpha$ is the constant phase exponent.

It is well known that the OER process is more complicated than the HER process, involving many intermediate steps before $\mathrm{OH}^{-}$completely converts to $\mathrm{O}_{2} / \mathrm{H}_{2} \mathrm{O}$. In the present work, we use both ECs in Figure 2 to evaluate the OER activity. The 2R-CPE model consists of series resistance and two R-CPE combinations (Figure $2 b$ ), which represent series resistance $\left(R_{1}\right)$, film/barrier impedance $\left(C P E_{f}\right.$ and $\left.R_{2}\right)$, and the OER related interfacial reactions $\left(\mathrm{CPE}_{\mathrm{dl}}\right.$ and $\left.\mathrm{R}_{3}\right)$. The underlying assumption behind the EC of Figure $2 \mathrm{~b}$ is that 
the $\mathrm{L}-\mathrm{R}_{4}$ series combination can be neglected since its effect is too small to be measurable in the frequency range of interest.

(a)

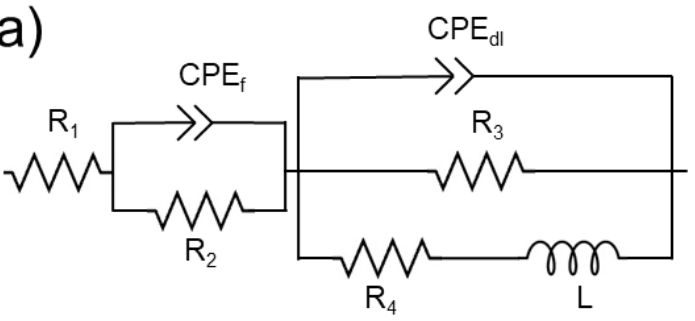

(b)

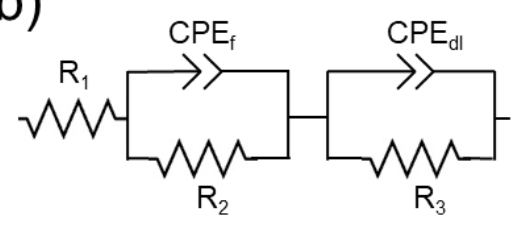

Figure 2. ECs models abbreviated L-CPE (a) and 2R-CPE (b) used for fitting data of as-prepared catalysts.

The CPE is used as a pseudo-capacitive element corresponding to a combination of capacitive and charge-transfer processes, influenced by electrode roughness, porosity, and inhomogeneity. It is frequently used to model the influence of surface heterogeneity on the double-layer behavior, and it is of considerable interest to derive an effective capacitance value from the CPE model. When $\alpha=1, \mathrm{Q}$ represents the capacitance of the interface in units of $\mathrm{F} / \mathrm{cm}^{2}$. When $\alpha<1$, the system shows interfacial behavior that is attributed to surface heterogeneity or to continuously distributed time constants for charge-transfer reactions. The parameter $\mathrm{Q}$ of $\mathrm{CPE}$ cannot represent the capacitance when $\alpha<1$. Previously, both the Mansfeld formula [42] and the Brug formula [38] have been widely used to extract effective equivalent capacitances from CPE parameters [43-45]. To ascertain the suitability of these formulae for our system, they were used to extract values of the effective equivalent capacitance. In the case of a surface time-constant distribution, Brug et al. [38] obtained a relationship between interfacial capacitance and CPE parameters for both Faradaic and blocking systems. For the case in Figure 2, the double-layer capacitance can be described by

$$
C_{d l}=Q^{\frac{1}{\alpha}}\left[\left(R_{1}+R_{2}\right)^{-1}+R_{3}^{-1}\right]^{(\alpha-1) / \alpha}
$$

Hsu and Mansfeld [42] suggested a different relationship in terms of $Q, \alpha$ based on the characteristic frequency where the imaginary part of the impedance obtains its maximum magnitude. According to the specific case in this study, the double-layer capacitance can be expressed as

$$
C_{\mathrm{dl}}=Q^{\frac{1}{\alpha}} R_{3}(1-\alpha) / \alpha
$$

Figure 3a shows the HER performance obtained by LSV, of Fe-NiO and $\mathrm{NiO}$ nanosheets on $\mathrm{Ni}$ foam, measured in $1 \mathrm{M} \mathrm{NaOH}$ solution without iR compensation in a three-electrode electrochemical configuration. The HER efficiency of Fe-NiO nanosheets is better than that of $\mathrm{NiO}$ nanosheets, where the overpotential of $\mathrm{Fe}-\mathrm{NiO}$ nanosheets is $34 \mathrm{mV}$ lower than that of $\mathrm{NiO}$ nanosheets at $10 \mathrm{~mA} \mathrm{~cm}{ }^{-2}$. Figure $3 b, c$, together with the lower potential data depicted in Figure S4, present the experimental Nyquist plots, for Fe-NiO and $\mathrm{NiO}$ nanosheets, of the $\mathrm{AC}$ response in a selected potential range from $-1 \mathrm{~V}$ to $-1.4 \mathrm{~V}$ vs. $\mathrm{Ag} / \mathrm{AgCl}(3 \mathrm{M}$ $\mathrm{KCl}$ ), respectively. For the HER process, there is a negative loop in the low-frequency range, which means that an inductive element in the EC is needed. An analysis based on the theoretical model of Figure 2a reveals that the series resistance because of the electrolyte, as well as the high-frequency resistance and capacitance, are independent of the electrode type and the applied bias (Figure 3d,e). The fitting shows a perfect capacitive behavior in the high-frequency range, which means that the exponent $\alpha$ is equal to 1 . In terms of classical electrostatics, the capacitance of a layer is given by $\mathrm{C}=\mathrm{A} \varepsilon \varepsilon_{0} / \mathrm{d}$, where $\mathrm{A}$ is geometrical area, $\mathrm{d}$ is thickness, $\varepsilon$ is the dielectric permittivity of the material, and $\varepsilon_{0}$ is the permittivity of free space. Assuming a literature value of $\varepsilon=1000[46,47]$ for $\mathrm{NiO}$ and neglecting effects of porosity, we estimate that $\mathrm{d} \sim 1 \mu \mathrm{m}$. This order of magnitude agrees with the thickness of the nanosheets as shown in Figure S2. The film capacitance $\mathrm{C}_{\mathrm{f}}$ of $\mathrm{NiO}$ nanosheets is slightly larger than that of $\mathrm{Fe}-\mathrm{NiO}$ nanosheets, which is likely due to the different surface 
roughness observed in Figure 1, Figures S1 and S2. In addition, from Figure 3f,g, it is seen that the moderate to low-frequency response exhibits a strong dependence on the applied potential and electrode material, correlating with the reaction rate under the HER process. The variation in the values of $\mathrm{R}_{3}, \mathrm{R}_{4}$, and $\mathrm{L}$ for $\mathrm{Fe}-\mathrm{NiO}$ and $\mathrm{NiO}$ nanosheets as a function of DC potential is shown in Figure 3f,g. The smaller resistances $\left(R_{3}\right.$ and $\left.R_{4}\right)$ and inductance (L) of Fe-NiO nanosheets revealed that the presence of Fe could promote the hydrogenrelated charge transfer and coverage relaxation related to adsorbed intermediates, thereby enhancing the HER catalytic activity. In addition, Figure 3f,g also show that the inductive behavior depends on the applied potential. Furthermore, Diard et al. [48] reported that the inductive behavior can only be observed in the case that the Volmer-Heyrovsky mechanism is the rate-determining. Hence, our data show that the rate of HER is determined by the Volmer-Heyrovsky reaction steps in the $\mathrm{Fe}-\mathrm{NiO}$ and $\mathrm{NiO}$ systems. The HER mechanism is also investigated by empirical Tafel plots in Figure S5. It is shown that the Tafel slopes of $\mathrm{Fe}-\mathrm{NiO}$ and $\mathrm{NiO}$ nanosheets are $105.5 \mathrm{mV} \mathrm{dec}^{-1}$ and $108.1 \mathrm{mV} \mathrm{dec}^{-1}$, respectively, which is between the theoretical values for the rate-determining Volmer $\left(120 \mathrm{mV} \mathrm{dec}^{-1}\right)$ and Heyrovsky $\left(40 \mathrm{mV} \mathrm{dec}^{-1}\right)$ cases, and thus, further indicates that the HER is proceeding via a Volmer-Heyrovsky reaction.
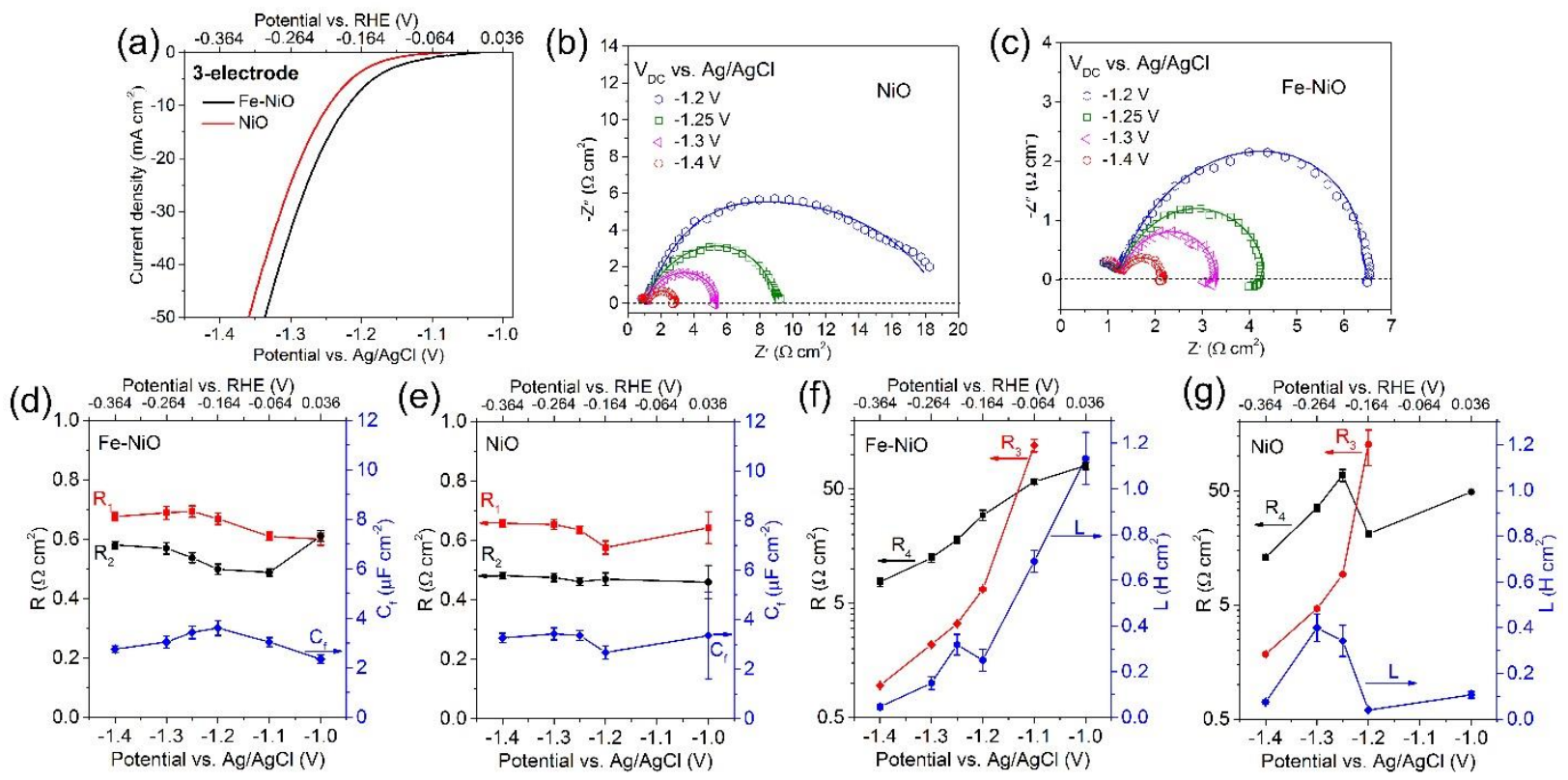

Figure 3. (a) Cathodic polarization curves of $\mathrm{Fe}-\mathrm{NiO}$ and $\mathrm{NiO}$ nanosheets on $\mathrm{Ni}$ foam, at a scan rate of $1 \mathrm{mV} \mathrm{s}^{-1}$. EIS plots for (b) $\mathrm{NiO}$ and (c) $\mathrm{Fe}-\mathrm{NiO}$ nanosheets at different DC potentials vs. $\mathrm{Ag} / \mathrm{AgCl}(3 \mathrm{M} \mathrm{KCl})$ under the HER process. The symbols show the experimental points, while solid lines are the fitting curves using the EC of Figure 2a. (d-g) Circuit element values calculated from the fits of EIS data of porous Fe-NiO and $\mathrm{NiO}$ films to the EC of Figure $2 \mathrm{a}$. The values of $\mathrm{R}_{3}$ at the smallest negative potentials were not plotted in $(\mathbf{f})$ and $(\mathrm{g})$ because they could not be determined accurately by the EC fitting.

The L-CPE model enabled us to separate the contribution from the double layer capacitance from the response due to the change of surface coverage of adsorbed species, which is determined by the $L-R_{4}$ arm in Figure $2 a$. The pseudocapacitance $Q$ and exponent $\alpha$ obtained from the double layer element, $\mathrm{CPE}_{\mathrm{dl}}$, for HER is shown in Figure S6. The value of the effective double-layer capacitance was estimated by Equations (2) and (3), respectively. As shown in Figure 4, it is clear that the Brug formula gives a well-defined value of effective capacitance, independent of potential, for our porous film, even though the exponent $\alpha$ is considerably lower than unity (Figure S6). We found consistently a double layer capacitance of 0.2 to $0.3 \mathrm{mF} \mathrm{cm}{ }^{-2}$. The values obtained from the Mansfeld formula were in good agreement with the Brug ones at potentials below $-1.25 \mathrm{~V}$ but showed an unphysical dependence on potential above $-1.25 \mathrm{~V}$. 

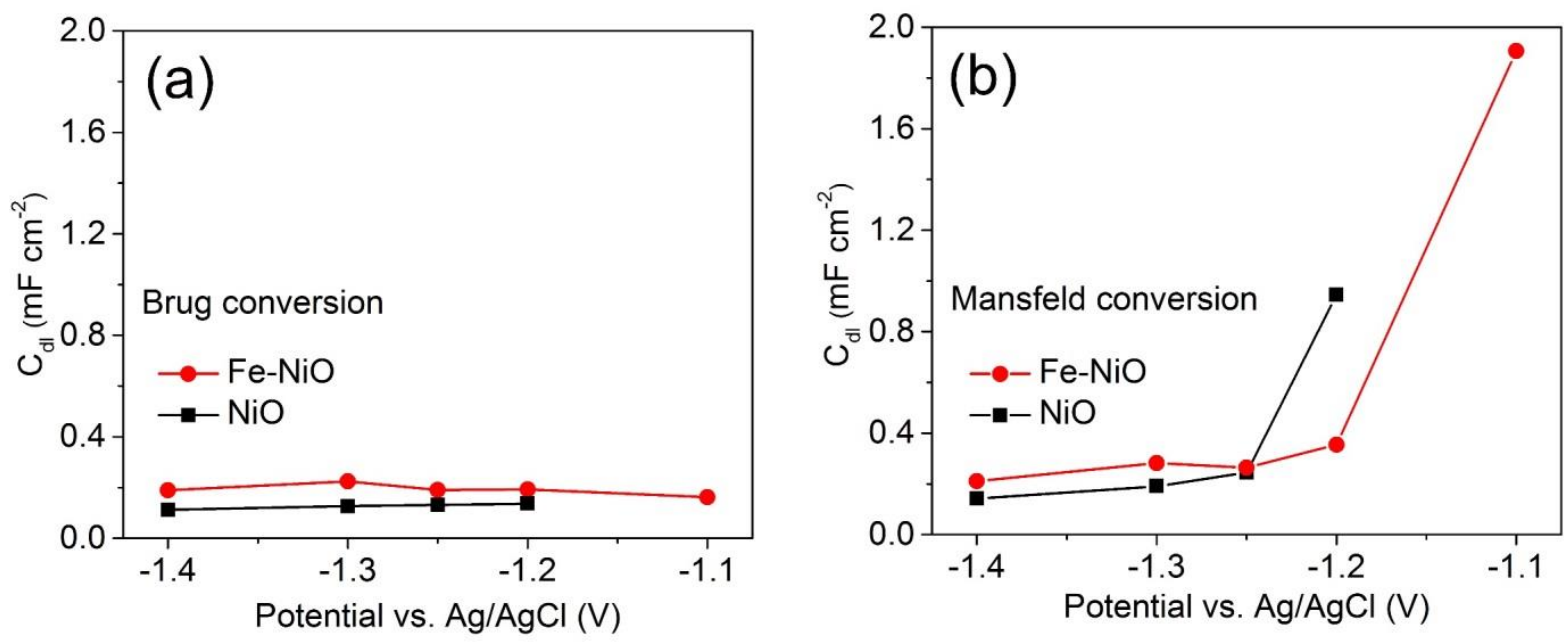

Figure 4. The effective double layer capacitance was calculated from the Brug equation (a) and the Mansfeld equation (b) as a function of applied potential under the HER process in $1 \mathrm{M} \mathrm{NaOH}$.

Figure 5a shows the OER activities of $\mathrm{Fe}-\mathrm{NiO}$ and $\mathrm{NiO}$ nanosheets under the same conditions, which indicates that $\mathrm{Fe}$ incorporation into the $\mathrm{NiO}$ lattice is also positive for the OER, as many groups reported [22,49-51]. The electrochemical stability and prolonged activity of $\mathrm{Fe}-\mathrm{NiO}$ and $\mathrm{NiO}$ for both OER and HER were investigated by $\mathrm{i}-\mathrm{t}$ curves applying a constant anodic and cathodic overpotential, respectively. As seen in Figure S7, there was an insignificant change of current densities on $\mathrm{Fe}-\mathrm{NiO}$ and $\mathrm{NiO}$ under the same constant potential, which indicated that the enhanced activity of Fe-doped $\mathrm{NiO}$ was mainly due to Fe incorporation by synthesis rather than the incidental iron from the electrolyte. To investigate the performance of electrochemical cells, the overall water splitting was also measured using as-prepared catalysts as both anode and cathode in a two-electrode configuration (Figure S8). The polarization curves showed that bifunctional catalyst Fe$\mathrm{NiO}$ required only $1.73 \mathrm{~V}$ to reach a current density of $10 \mathrm{~mA} \mathrm{~cm}^{-2}$, which was $124 \mathrm{mV}$ lower than for $\mathrm{NiO}$. It complied well with the performance of $\mathrm{Fe}-\mathrm{NiO}$ and $\mathrm{NiO}$ catalysts for the half-reaction in a three-electrode configuration. For a detailed study of the Fe effect on the OER electrochemical process, EIS was carried out at different applied potentials from $0.3 \mathrm{~V}$ to $0.65 \mathrm{~V}$ vs. $\mathrm{Ag} / \mathrm{AgCl}(3 \mathrm{M} \mathrm{KCl})$. As shown in Figure $5 b, c$, the real and imaginary parts of impedance decreases with increasing applied potentials in the low-frequency range, while the high-frequency impedance is not changing appreciably with DC potential. It is clear that the behavior at low frequencies is related to the charge-transfer resistance and results in different OER catalytic properties. As shown in Figure 5b,c, Nyquist plots of $\mathrm{Fe}-\mathrm{NiO}$ and $\mathrm{NiO}$ contain two semicircles with no discernible negative loop at the lowfrequency range. Therefore, we interpreted the results by fits to the $2 \mathrm{R}$-CPE circuit in Figure $2 \mathrm{~b}$.

Figure $6 a, b$ show that the values of $R_{1}$ and $R_{2}$ exhibit negligible change with potential, while the value of $R_{3}$ decreases with increasing potential. As before, we attribute $R_{2}$ and $\mathrm{CPE}_{\mathrm{f}}$ to the transport properties in the electrode since the effective capacitance $\mathrm{C}_{\mathrm{f}}$ (Figure 6c-f) does not show any significant potential dependence. The pseudocapacitance $\mathrm{Q}$ and exponent $\alpha$ obtained from the CPE's for the OER case are shown in Figure S8a,b for the film capacitance and double layer capacitance, respectively. Figure $6 \mathrm{c}-\mathrm{f}$ compares the calculated values of $\mathrm{C}_{\mathrm{f}}$ and $\mathrm{C}_{\mathrm{dl}}$ obtained from the Brug equation and Mansfeld formula for $\mathrm{Fe}-\mathrm{NiO}$ nanosheets and $\mathrm{NiO}$ nanosheets in the case of the OER process. The two equations gave similar capacitance values, although $C_{\mathrm{dl}}$ could only be accurately evaluated at a few potentials due to uncertainties in the fit parameters. The double-layer capacitance $C_{d 1}$ of the $\mathrm{Fe}-\mathrm{NiO}$ and $\mathrm{NiO}$ nanosheets was found to be very high, larger than $50 \mathrm{mF} \mathrm{cm}{ }^{-2}$, but the data in Figure $6 \mathrm{c}-\mathrm{f}$ are observed to display strong potential dependence. The power-law exponents in Figure S9b are always lower than 0.7, indicating that diffusion effects may influence $\mathrm{CPE}_{\mathrm{dl}}$. Under these conditions, it was doubtful whether the results from the Brug 
and Mansfeld equations represented geometrical capacitances. The value of $\mathrm{R}_{3}$ of $\mathrm{Fe}-\mathrm{NiO}$ nanosheets was smaller than that of $\mathrm{NiO}$ nanosheets at the same potential with e.g., a 7 -fold decrease of reaction resistance at $0.6 \mathrm{~V}$ (Figure $6 \mathrm{a}, \mathrm{b}$ ). This implied a major reduction in reaction resistance by the presence of $\mathrm{Fe}$, facilitating the yield of oxygen generation.
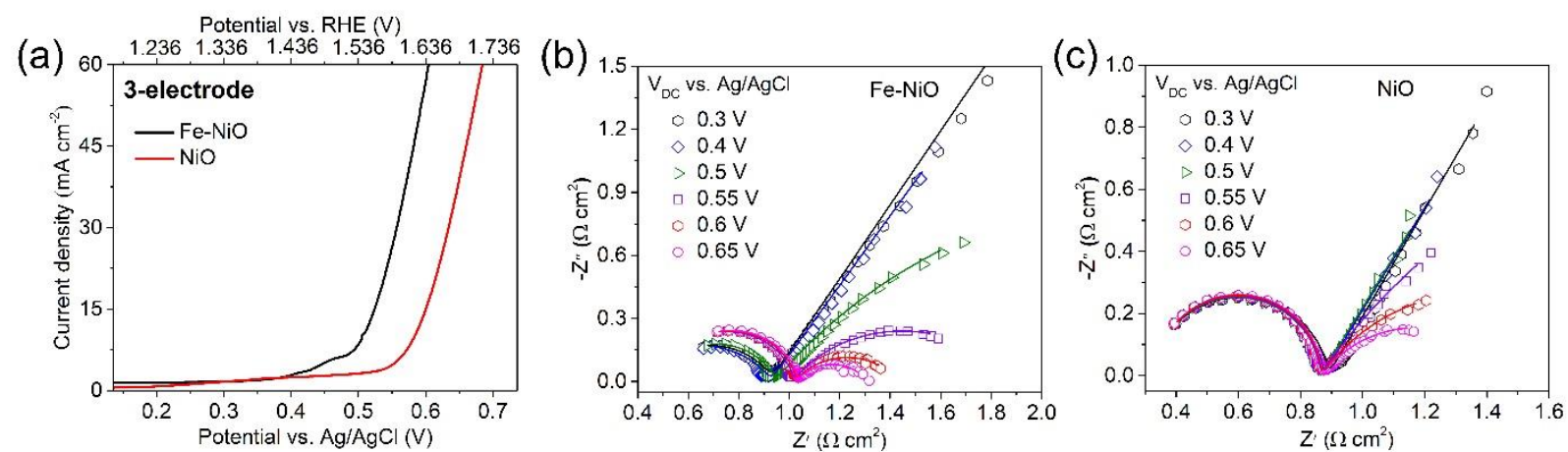

Figure 5. (a) Anodic polarization curves of $\mathrm{Fe}-\mathrm{NiO}$ and $\mathrm{NiO}$ nanosheets on $\mathrm{Ni}$ foam without iR correction, taken at a scan rate of $1 \mathrm{mV} \mathrm{s}^{-1}$. Impedance curves for OER at different DC potentials vs. $\mathrm{Ag} / \mathrm{AgCl}(3 \mathrm{M} \mathrm{KCl})$ on porous $\mathrm{Fe}-\mathrm{NiO}$ (b) and $\mathrm{NiO}$ (c) nanosheets. The symbols show the experimental points, while solid lines are the fitting curves using the EC of Figure 2b (2R-CPE).

It is not possible to determine by inspection of the measured OER impedance plots in Figure 5 whether the asymptotic low-frequency response is inductive or capacitive. This issue was of considerable importance for the determination of rate-determining reaction mechanisms. There was no visible inductive loop in the low-frequency range shown in the measured OER impedance plots in Figure 5, but similar mechanisms of adsorption and desorption of surface species under the OER process, as under the HER one, should exist. To study this effect in more detail, we attempted to fit the OER experimental data to the L-CPE circuit in Figure 2a but allowing the inductance $\mathrm{L}$ to be both positive and negative, to be able to distinguish between capacitive and inductive behavior. However, fitting to the EC in Figure 2a was only possible at potentials in the range $0.5-0.7 \mathrm{~V}$ vs. $\mathrm{Ag} / \mathrm{AgCl}$ (Figure 7), since the model over-parametrized the data at lower potentials. Because only a part of the low-frequency semicircle can be seen in Figure $5 b$ and, especially in Figure $5 c$, these fits gave a very large uncertainty in many of the circuit elements in the L-CPE model. Preliminary fits indicated that $\mathrm{R}_{4}$ was very small and to decrease the number of parameters, it was put equal to zero. This assumption led to acceptable uncertainties in the other circuit parameters at potentials in the range 0.5 to $0.7 \mathrm{~V}$, especially for the case of $\mathrm{Fe}-\mathrm{NiO}$ nanosheets. As shown in Figure S10, the parameter values and their trends were similar to those shown in Figure 6, in most cases even quantitatively, for the case of the $\mathrm{Fe}-\mathrm{NiO}$ nanosheets. However, it was more difficult to use the L-CPE circuit for the $\mathrm{NiO}$ nanosheets, since parameter uncertainties were higher, and some parameters could not be obtained at all potentials. In the case of $\mathrm{NiO}, \mathrm{R}_{1}, \mathrm{R}_{2}$, and $\mathrm{C}_{\mathrm{f}}$ exhibited the same trend as in the fit to the simpler circuit $2 \mathrm{R}-\mathrm{CPE}$ (Figure 6), while $\mathrm{R}_{3}$ and $\mathrm{C}_{\mathrm{dl}}$ showed larger discrepancies. The main new and important result obtained from the fits to the L-CPE circuit was that positive values of inductance were consistently obtained (Figure S10a,b). This indicated the presence of an inductive loop but at very low frequencies beyond the range used in our measurements. Furthermore, this suggested that the relaxation due to the change of surface coverage of reaction intermediates was asymptotically inductive also for the OER process in alkaline electrolytes. 

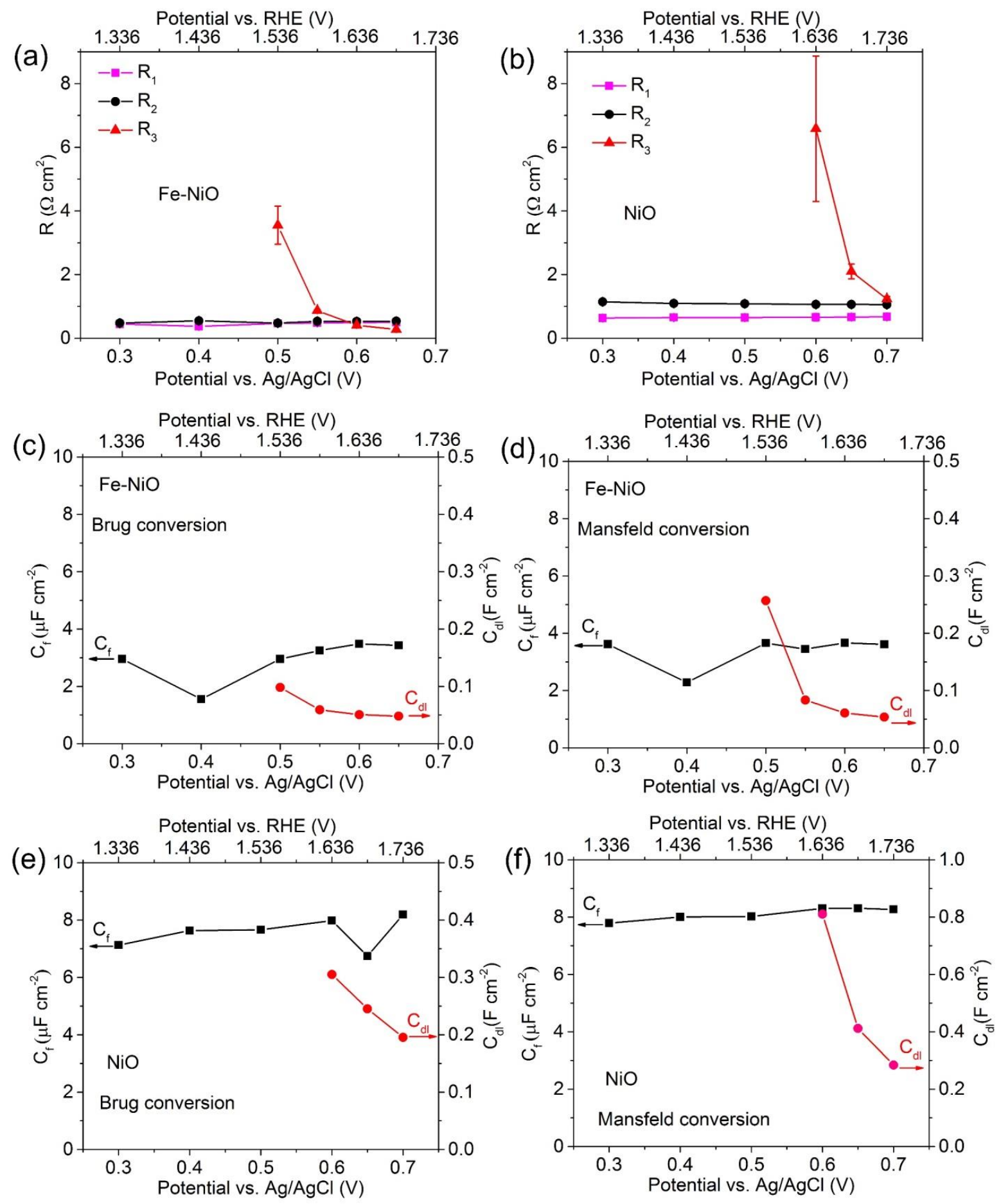

Figure 6. Circuit element values calculated from the fits of EIS data of porous Fe-NiO and NiO films to the EC of Figure $2 \mathrm{~b}$. Resistances $(\mathbf{a}, \mathbf{b})$ and effective equivalent capacitances $(\mathbf{c}-\mathbf{f})$ are shown as a function of applied potentials. 

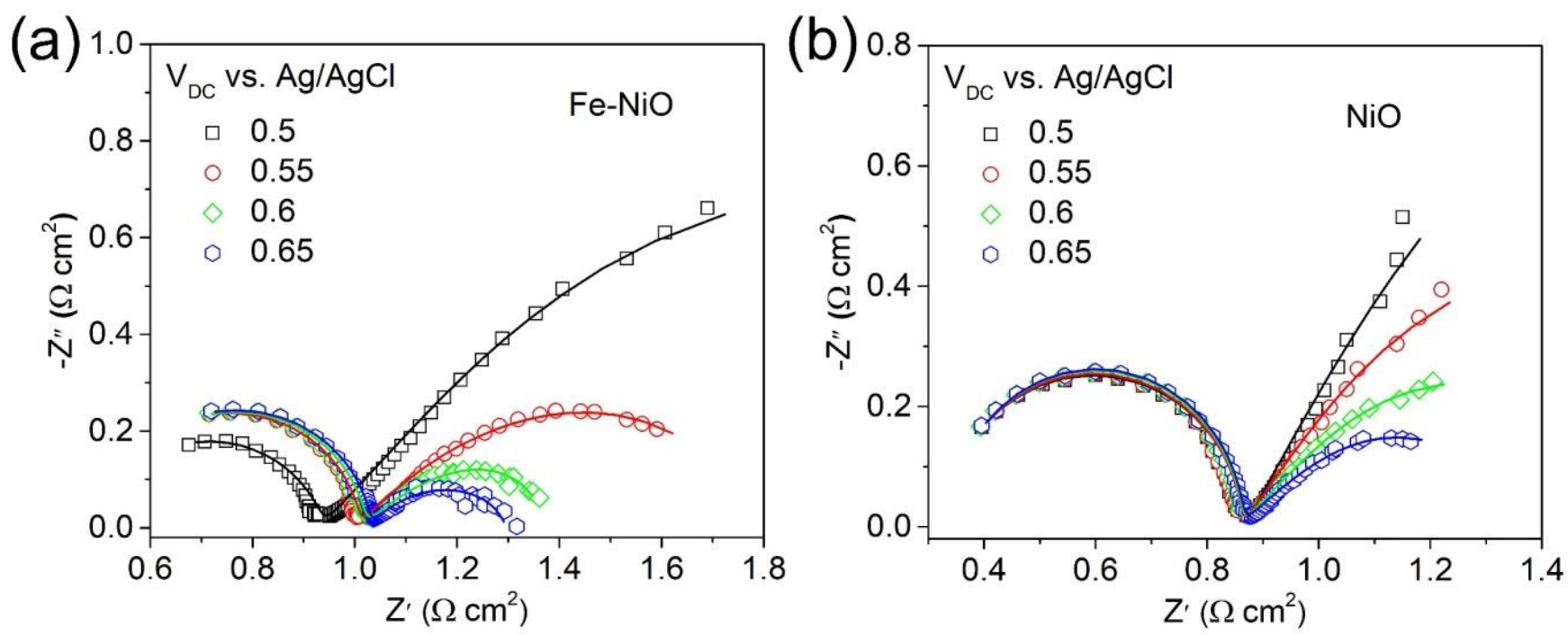

Figure 7. Nyquist plots obtained at different applied potentials vs. $\mathrm{Ag} / \mathrm{AgCl}(3 \mathrm{M} \mathrm{KCl})$ on porous $\mathrm{Fe}-\mathrm{NiO}(\mathbf{a})$ and $\mathrm{NiO}$ (b) nanosheets in $1 \mathrm{M} \mathrm{NaOH}$. The data were also shown in Figure 5. Symbols denote experimental data and full lines are fitted by the L-CPE model.

\section{Conclusions}

In summary, in comparison with $\mathrm{NiO}$ nanosheets, $\mathrm{Fe}$ doped $\mathrm{NiO}$ nanosheets exhibit enhanced catalytic activities for both OER and HER in alkaline electrolytes. We explored the electrochemical impedance response of $\mathrm{Fe}-\mathrm{NiO}$ and $\mathrm{NiO}$ nanosheets and investigated two different equivalent circuit models to obtain values of specific physical parameters characterizing the OER and HER. A model including an inductance, the L-CPE model, is theoretically justified for the HER and yields excellent fits to experimental data. The low-frequency behavior is inductive, which shows that the Volmer-Heyrovsky steps are rate determining. This model can in principle be used also for the OER, giving excellent fits, although many parameter values become uncertain. However, the modeling shows the lowfrequency impedance to be asymptotically inductive also for the case of the OER. Hence the L-CPE model provides a new strategy to understand the OER process pathway, in cases where data are accurate enough to distinguish it from the simpler empirical 2R-CPE model. The EC modeling quantitatively shows that Fe doping lowers the charge transfer resistance, i.e., the reaction barrier for water splitting on the $\mathrm{NiO}$ nanosheets, promotes the reaction activity, and accelerates the transformation of absorbed intermediates in agreement with a recently published study using operando Raman spectroscopy [23]. Our findings provide an EIS approach for an improved understanding of the catalytic reaction mechanism, which is ultimately beneficial for the design and characterization of efficient and low-cost catalyst systems.

Supplementary Materials: The following are available online at https://www.mdpi.com/article/ 10.3390/physchem1010005/s1, Figure S1: (a) Low and (b) high magnification SEM images of NiO nanosheets, Figure S2: The thickness of Fe-NiO nanosheets (a) and $\mathrm{NiO}$ nanosheets (b) measured by SEM images, Figure S3: (a) XRD patterns of Fe-NiO and $\mathrm{NiO}$ nanosheets as well as the subatrate $\mathrm{Ni}$ foam, (b) corresponding magnified image of portions of figure (a), Figure S4: EIS plots for $\mathrm{Fe}-\mathrm{NiO}$ (a) and $\mathrm{NiO}$ (b) nanosheets at different $\mathrm{DC}$ potentials vs. $\mathrm{Ag} / \mathrm{AgCl}(3 \mathrm{M} \mathrm{KCl})$ under HER process, Figure S5: The corresponding cathodic Tafel plots at a scan rate of $1 \mathrm{mV} \mathrm{s}^{-1}$ via a three-electrode configuration in $1 \mathrm{M} \mathrm{NaOH}$ aqueous elelctrolyte, Figure S6: The pseudo capacitance $Q$ and exponent $\alpha$ of the double layer capacitance as a function ofpotential for HER, Figure S7: J-t curves of Fe-NiO and $\mathrm{NiO}$ nanosheets on $\mathrm{Ni}$ foam at $1.636 \mathrm{~V}$ and $-0.214 \mathrm{~V}$ vs. RHE for $12 \mathrm{~h}$ in $1 \mathrm{M} \mathrm{NaOH}$, Figure S8: Comparison of polarization curves of the overall water splitting using $\mathrm{Fe}-\mathrm{NiO}$ and $\mathrm{NiO}$ as both anode and cathode in a two-electrode configuration at the scan rate of $1 \mathrm{mV} \mathrm{s}^{-1}$ in $1 \mathrm{M} \mathrm{NaOH}$, Figure S9: The pseudo capacitance $Q$ and exponent $\alpha$ of the film (a) and the double layer capacitance (b) as 
a function of potential for OER, Figure S10: Circuit element values calculated from the fits of EIS data of porous $\mathrm{Fe}-\mathrm{NiO}$ and $\mathrm{NiO}$ films to the $\mathrm{EC}$ in Fig. 2a. Inductance and resistances $(\mathrm{a}, \mathrm{b})$ as well as effective equivalent capacitances (c-f) are shown as a function of applied potential, error bars for the fit parameters are shown in (a) and (b).

Author Contributions: Z.Q. and T.E. initialized the research project and conceptualized the approach. Z.Q. performed the experimental work and analysis. Y.M. helped with material synthesis. G.A.N. and T.E. provided the idea to improve the equivalent circuit model and participated in the impedance analysis. Z.Q. and T.E. wrote the original draft and all authors participated in reviewing and editing the final manuscript. Project administration, T.E.; funding acquisition, G.A.N., T.E. All authors have read and agreed to the published version of the manuscript.

Funding: This research was funded by the Swedish Energy Agency, the Swedish Research Council (VR 2015-03814; VR 2016-03713), and the Swedish Research Council for sustainable development (2016-00908).

Institutional Review Board Statement: Not applicable.

Informed Consent Statement: Not applicable.

Data Availability Statement: Not applicable.

Conflicts of Interest: The authors declare no conflict of interest.

\section{References}

1. Schlapbach, L.; Zuttel, A. Hydrogen-storage materials for mobile applications. Nature 2001, 414, 353-358. [CrossRef]

2. Gasteiger, H.A.; Markovic, N.M. Chemistry. Just a dream-or future reality? Science 2009, 324, 48-49. [CrossRef] [PubMed]

3. Ardo, S.; Rivas, D.F.; Modestino, M.A.; Greiving, V.S.; Abdi, F.F.; Llado, E.A.; Artero, V.; Ayers, K.; Battaglia, C.; Becker, J.P.; et al. Pathways to electrochemical solar-hydrogen technologies. Energy Environ. Sci. 2018, 11, 2768-2783. [CrossRef]

4. Shi, Y.; Zhang, B. Recent advances in transition metal phosphide nanomaterials: Synthesis and applications in hydrogen evolution reaction. Chem. Soc. Rev. 2016, 45, 1529-1541. [CrossRef] [PubMed]

5. Anantharaj, S.; Ede, S.R.; Sakthikumar, K.; Karthick, K.; Mishra, S.; Kundu, S. Recent Trends and Perspectives in Electrochemical Water Splitting with an Emphasis on Sulfide, Selenide, and Phosphide Catalysts of Fe, Co, and Ni: A Review. ACS Catal 2016, 6 , 8069-8097. [CrossRef]

6. Yan, Y.; Xia, B.Y.; Zhao, B.; Wang, X. A review on noble-metal-free bifunctional heterogeneous catalysts for overall electrochemical water splitting. J. Mater. Chem. A 2016, 4, 17587-17603. [CrossRef]

7. Corrigan, D.A. The Catalysis of the Oxygen Evolution Reaction by Iron Impurities in Thin-Film Nickel-Oxide Electrodes. J. Electrochem. Soc. 1987, 134, 377-384. [CrossRef]

8. Miller, E.L. Electrochemical Behavior of Reactively Sputtered Iron-Doped Nickel Oxide. J. Electrochem. Soc. 1997, 144, 3072-3077. [CrossRef]

9. Trotochaud, L.; Young, S.L.; Ranney, J.K.; Boettcher, S.W. Nickel-iron oxyhydroxide oxygen-evolution electrocatalysts: The role of intentional and incidental iron incorporation. J. Am. Chem Soc. 2014, 136, 6744-6753. [CrossRef]

10. Wang, P.; Pu, Z.; Li, Y.; Wu, L.; Tu, Z.; Jiang, M.; Kou, Z.; Amiinu, I.S.; Mu, S. Iron-Doped Nickel Phosphide Nanosheet Arrays: An Efficient Bifunctional Electrocatalyst for Water Splitting. ACS Appl Mater. Interfaces 2017, 9, 26001-26007. [CrossRef]

11. Luo, J.; Im, J.H.; Mayer, M.T.; Schreier, M.; Nazeeruddin, M.K.; Park, N.G.; Tilley, S.D.; Fan, H.J.; Gratzel, M. Water photolysis at 12.3\% efficiency via perovskite photovoltaics and Earth-abundant catalysts. Science 2014, 345, 1593-1596. [CrossRef] [PubMed]

12. Smith, R.D.; Prevot, M.S.; Fagan, R.D.; Trudel, S.; Berlinguette, C.P. Water oxidation catalysis: Electrocatalytic response to metal stoichiometry in amorphous metal oxide films containing iron, cobalt, and nickel. J. Am. Chem Soc. 2013, 135, 11580-11586. [CrossRef] [PubMed]

13. Fillol, J.L.; Codola, Z.; Garcia-Bosch, I.; Gomez, L.; Pla, J.J.; Costas, M. Efficient water oxidation catalysts based on readily available iron coordination complexes. Nat. Chem 2011, 3, 807-813. [CrossRef] [PubMed]

14. Singh, A.; Chang, S.L.Y.; Hocking, R.K.; Bach, U.; Spiccia, L. Highly active nickel oxide water oxidation catalysts deposited from molecular complexes. Energy Environ. Sci. 2013, 6, 579-586. [CrossRef]

15. Młynarek, G.; Paszkiewicz, M.; Radniecka, A. The effect of ferric ions on the behaviour of a nickelous hydroxide electrode. J. Appl. Electrochem. 1984, 14, 145-149. [CrossRef]

16. Delgado, D.; Minakshi, M.; Kim, D.J.; Kyeong, C. Influence of the Oxide Content in the Catalytic Power of Raney Nickel in Hydrogen Generation. Anal. Lett. 2017, 50, 2386-2401. [CrossRef]

17. Friebel, D.; Louie, M.W.; Bajdich, M.; Sanwald, K.E.; Cai, Y.; Wise, A.M.; Cheng, M.-J.; Sokaras, D.; Weng, T.-C.; Alonso-Mori, R.; et al. Identification of Highly Active Fe Sites in (Ni,Fe)OOH for Electrocatalytic Water Splitting. J. Am. Chem. Soc. 2015, 137, 1305-1313. [CrossRef]

18. Kim, S.; Tryk, D.A.; Antonio, M.R.; Carr, R.; Scherson, D. In situ x-ray absorption fine structure studies of foreign metal ions in nickel hydrous oxide electrodes in alkaline electrolytes. J. Phys. Chem. 1994, 98, 10269-10276. [CrossRef] 
19. Del Arco, M.; Malet, P.; Trujillano, R.; Rives, V. Synthesis and Characterization of Hydrotalcites Containing Ni(II) and Fe(III) and Their Calcination Products. Chem. Mater. 1999, 11, 624-633. [CrossRef]

20. Chen, J.Y.C.; Dang, L.; Liang, H.; Bi, W.; Gerken, J.B.; Jin, S.; Alp, E.E.; Stahl, S.S. Operando Analysis of NiFe and Fe Oxyhydroxide Electrocatalysts for Water Oxidation: Detection of Fe4+ by Mössbauer Spectroscopy. J. Am. Chem. Soc. 2015, 137, 15090-15093. [CrossRef]

21. Qiu, Z.; Tai, C.-W.; Niklasson, G.A.; Edvinsson, T. Direct observation of active catalyst surface phases and the effect of dynamic self-optimization in NiFe-layered double hydroxides for alkaline water splitting. Energy Environ. Sci. 2019, 12, 572-581. [CrossRef]

22. Li, Y.F.; Selloni, A. Mechanism and Activity of Water Oxidation on Selected Surfaces of Pure and Fe-Doped NiOx. ACS Catal. 2014, 4, 1148-1153. [CrossRef]

23. Qiu, Z.; Ma, Y.; Edvinsson, T. In operando Raman investigation of Fe doping influence on catalytic NiO intermediates for enhanced overall water splitting. Nano Energy 2019, 66, 104118. [CrossRef]

24. Lvovich, V.F. Impedance Spectroscopy: Applications to Electrochemical and Dielectric Phenomena; John Wiley \& Sons: Hoboken, NJ, USA, 2012.

25. Barsoukov, E.; Macdonald, J.R. Impedance Spectroscopy: Theory, Experiment, and Applications; John Wiley \& Sons: Hoboken, NJ, USA, 2018.

26. Harrington, D.A.; Conway, B.E. ac Impedance of Faradaic reactions involving electrosorbed intermediates-I. Kinetic theory. Electrochim. Acta 1987, 32, 1703-1712. [CrossRef]

27. Wu, Z.C.; Zou, Z.X.; Huang, J.S.; Gao, F. Fe-doped NiO mesoporous nanosheets array for highly efficient overall water splitting. J. Catal. 2018, 358, 243-252. [CrossRef]

28. Liu, S.H.; Jia, J.F.; Wang, J.; Liu, S.J.; Wang, X.C.; Song, H.Z.; Hu, X. Synthesis of Fe-doped NiO nanofibers using electrospinning method and their ferromagnetic properties. J. Magn. Magn. Mater. 2012, 324, 2070-2074. [CrossRef]

29. Fominykh, K.; Chernev, P.; Zaharieva, I.; Sicklinger, J.; Stefanic, G.; Doblinger, M.; Muller, A.; Pokharel, A.; Bocklein, S.; Scheu, C.; et al. Iron-doped nickel oxide nanocrystals as highly efficient electrocatalysts for alkaline water splitting. ACS Nano 2015, 9 , 5180-5188. [CrossRef]

30. Dietz, R.E.; Parisot, G.I.; Meixner, A.E. Infrared Absorption and Raman Scattering by Two-Magnon Processes in NiO. Phys. Rev. B 1971, 4, 2302-2310. [CrossRef]

31. Fleury, P.A.; Loudon, R. Scattering of Light by One- and Two-Magnon Excitations. Phys. Rev. 1968, 166, 514-530. [CrossRef]

32. Aytan, E.; Debnath, B.; Kargar, F.; Barlas, Y.; Lacerda, M.M.; Li, J.X.; Lake, R.K.; Shi, J.; Balandin, A.A. Spin-Phonon Coupling in Antiferromagnetic Nickel Oxide. Appl. Phys. Lett. 2017, 111, 252402. [CrossRef]

33. Mironova-Ulmane, N.; Kuzmin, A.; Steins, I.; Grabis, J.; Sildos, I.; Pärs, M. Raman Scattering in Nanosized Nickel Oxide NiO. J. Phys. Conf. Ser. 2007, 93, 012039. [CrossRef]

34. Funkenbusch, E.F.; Cornilsen, B.C. Two-Magnon Raman Scattering in Calcium Doped NiO. Solid State Commun. 1981, 40, 707-710. [CrossRef]

35. Wang, J.; Cai, J.; Lin, Y.-H.; Nan, C.-W. Room-Temperature Ferromagnetism Observed in Fe-Doped NiO. Appl. Phys. Lett. 2005, 87, 202501. [CrossRef]

36. Ponnusamy, P.M.; Agilan, S.; Muthukumarasamy, N.; Senthil, T.S.; Rajesh, G.; Venkatraman, M.R.; Velauthapillai, D. Structural, optical and magnetic properties of undoped $\mathrm{NiO}$ and $\mathrm{Fe}$-doped $\mathrm{NiO}$ nanoparticles synthesized by wet-chemical process. Mater. Charact. 2016, 114, 166-171. [CrossRef]

37. Bai, L.; Conway, B.E. AC Impedance of Faradaic Reactions Involving Electrosorbed Intermediates: Examination of Conditions Leading to Pseudoinductive Behavior Represented in Three-Dimensional Impedance Spectroscopy Diagrams. J. Electrochem. Soc. 1991, 138, 2897-2907. [CrossRef]

38. Brug, G.J.; Van den Eeden, A.L.G.; Sluyters-Rehbach, M.; Sluyters, J.H. The Analysis of Electrode Impedances Complicated by the Presence of a Constant Phase Element. J. Electroanal Chem 1984, 176, 275-295. [CrossRef]

39. Diard, J.P.; LeGorrec, B.; Montella, C. Non-linear impedance for a two-step electrode reaction with an intermediate adsorbed species. Electrochim. Acta 1997, 42, 1053-1072. [CrossRef]

40. Dinh, C.T.; Jain, A.; de Arquer, F.P.G.; De Luna, P.; Li, J.; Wang, N.; Zheng, X.L.; Cai, J.; Gregory, B.Z.; Voznyy, O.; et al. Multi-site electrocatalysts for hydrogen evolution in neutral media by destabilization of water molecules. Nat. Energy 2019, 4, 107-114. [CrossRef]

41. Conway, B.E.; Tilak, B.V. Behavior and characterization of kinetically involved chemisorbed intermediates in electrocatalysis of gas evolution reactions. In Advances in Catalysis; Eley, D.D., Pines, H., Weisz, P.B., Eds.; Academic Press: San Diego, CA, USA, 1992; Volume 38, pp. 1-147.

42. Hsu, C.H.; Mansfeld, F. Technical Note: Concerning the Conversion of the Constant Phase Element Parameter Y0 into a Capacitance. Corrosion 2001, 57, 747-748. [CrossRef]

43. Elezović, N.R.; Jović, V.D.; Krstajić, N.V. Kinetics of the hydrogen evolution reaction on Fe-Mo film deposited on mild steel support in alkaline solution. Electrochim. Acta 2005, 50, 5594-5601. [CrossRef]

44. Chen, L. Study of the Kinetics of Hydrogen Evolution Reaction on Nickel-Zinc Alloy Electrodes. J. Electrochem. Soc. 1991, 138, 3321-3328. [CrossRef]

45. Van Schaftinghen, T.; Deslouis, C.; Hubin, A.; Terryn, H. Influence of the surface pre-treatment prior to the film synthesis, on the corrosion protection of iron with polypyrrole films. Electrochim. Acta 2006, 51, 1695-1703. [CrossRef] 
46. Nilsson, T.M.J.; Niklasson, G.A. Comparison of dielectric and optical properties of nickel-oxide-based electrochromic coatings. Proc. Spie 1990, 1272, 129-138.

47. Biju, V.; Khadar, M.A. Dielectric properties of nanostructured nickel oxide. J. Mater. Sci. 2003, 38, 4055-4063. [CrossRef]

48. Diard, J.P.; LeGorrec, B.; Maximovitch, S. Etude de l'activation du degagement d'hydrogene sur electrode d'oxyde de nickel par spectroscopie d'impedance. Electrochim. Acta 1990, 35, 1099-1108. [CrossRef]

49. Qi, J.; Zhang, W.; Xiang, R.; Liu, K.; Wang, H.-Y.; Chen, M.; Han, Y.; Cao, R. Porous Nickel-Iron Oxide as a Highly Efficient Electrocatalyst for Oxygen Evolution Reaction. Adv. Sci. 2015, 2, 1500199. [CrossRef]

50. Pebley, A.C.; Decolvenaere, E.; Pollock, T.M.; Gordon, M.J. Oxygen evolution on Fe-doped NiO electrocatalysts deposited via microplasma. Nanoscale 2017, 9, 15070-15082. [CrossRef]

51. Gong, M.; Dai, H. A mini review of NiFe-based materials as highly active oxygen evolution reaction electrocatalysts. Nano Res. 2015, 8, 23-39. [CrossRef] 